6. Trimm H. H. Analytical Chemistry: Methods and Applications / CRC Press. - 2011. - 380P.

7. Потапов В. О. До питання розрахунку внутрішніх джерел теплоти під час мікрохвильової обробки харчових продуктів/ В. О. Потапов, В. В. Качалов, С. В. Михайлова // Прогресивні техніка та технології харчових виробництв ресторанного господарства і торгівлі. - 2013. - Вип. 1(2). - С. 73-81.

8. Kostas E. T. The application of microwave heating in bioenergy: A review on the microwave pre-treatment and upgrading technologies for biomass. /E. T. Kostas, D. Beneroso, J. P. Robinson //Renewable and Sustainable Energy Reviews. - 2017. - 77. - P. 12-27.

9. Meda V. Microwave heating and the dielectric properties of foods / V. Meda, V. Orsat, V. Raghavan // The Microwave Processing of Foods (Second Edition) / V. Meda, V. Orsat, V. Raghavan. - Sawston: Woodhead Publishing, 2017. - P. 23-43.

References

1. Matsuska, O. V., Paranyak, R. P., Gumnytskyy, YA. M. (2011). "Purification of effluents from natural proteins by natural sorbents”, Naukovyy visnyk Lvivskoho natsionalnoho universytetu veterynarnoyi medytsyny ta biotekhnolohiy im. Gzhytskoho, vol. 13, № 2 (2), pp. 255-261.

2. Gumnytskyy, YA. M., Hyvlyud, A. M., Sabadash, V. V. (2015). "Kinetics of albumin adsorption by natural sorbent", Naukovi pratsi Odes'koyi natsional'noyi akademiyi kharchovykh tekhnolohiy, vol. 47 (1), pp. 133-137.

3. Beszédes, S., Szabó, G., Géczi, G. (2012). Application of thermal and microwave pre-treatments for dairy wastewater sludge, Annals of the Faculty of Engineering Hunedoara, vol. 10(3), pp. 231-235.

4. Sabadash V.V. (2018). "Purification of sewage in the field of ultrahigh-frequency radiation", Ucheni zapiski TNU named after V.I. Vernadsky Series: Engineering, vol. 29 (68), No 1, pp. 184-188.

5. Prates, L. L., Lei, Y., Refat, B., Zhang, W., Yu, P. (2018). Effects of heat processing methods on protein subfractions and protein degradation kinetics in dairy cattle in relation to protein molecular structure of barley grain using advanced molecular spectroscopy. Journal of Cereal Science, 80, 212-220.

6. Trimm, H. H. (Ed.). (2011). Analytical Chemistry: Methods and Applications. CRC Press.

7. Potapov, V. O., Kachalov, V. V., Mykhaylova, S. V. (2013). "To the question of calculation of internal sources of heat during microwave processing of food products", Prohresyvni tekhnika ta tekhnolohiyi kharchovykh vyrobnytstv restorannoho hospodarstva i torhivli, vol. 1 (2), pp. 73-81.

8. Kostas, E. T., Beneroso, D., Robinson, J. P. (2017). The application of microwave heating in bioenergy: A review on the microwave pre-treatment and upgrading technologies for biomass. Renewable and Sustainable Energy Reviews, 77, 12-27.

9. Meda, V., Orsat, V., Raghavan, V. (2017). Microwave heating and the dielectric properties of foods. In The Microwave Processing of Foods (Second Edition), pp. 23-43.

Отримано в редакцію 17.05 .2018

Прийнято до друку 30.06.2018

Received 17.05.2018

Approved 30.06.2018

УДК 662.997

DOI: http://dx.doi.org/10.15673/swonaft.v82i1.1012

\title{
ИНТЕГРАЦИЯ ПРОЦЕССА ТЕПЛООБМЕНА СОЛНЕЧНОЙ УСТАНОВКИ
}

\author{
Селихов Ю.А., канд. техн. наук., профессор, Коцаренко В.А., канд. техн. наук., профессор, \\ Национальный технический университет \\ «Харьковский политехнический институт», г. Харьков
}

\begin{abstract}
Аннотация. Европейские страны демонстрируют высокие возможности простого преобразования солнечной энергии в тепловую энергию, которая может успешно использоваться для обеспечения различного рода технологических, отопительных и бытовых потребностей. Кроме того, ввод в эксплуатаичю солнечных установок улучшает экологическую ситуацию района потребления тепловой энергии за счет снижения объемов выбросов загрязняющих веществ, к которым относятся продукты сгорания органического топлива, используемого для производства тепловой энергии. В настоящее время в южных районах Украины уже используются солнечные установки для горячего водоснабжения и отопления. Однако, внедрение новых энергетических и экономически выгодных установок идет медленными темпами, что объясняется довольно высокими стоимостными показателями, как отечественных, так и зарубежных установок. Таким образом, на наш взгляд, является актуальной концепция создания новых солнечных установок, наиболее привлекательных для потенциального потребителя. Реализация данной концепции возможна при таком варианте исполнения солнечных установок, когда затраты на выработку тепловой энергии с помощью этих установок будут ниже уровня суммарных затрат на получение тепловой энергии традиционными способами (в частности, в котельных установках). Одновременно с этим, срок окупаемости солнечных установок должен быть соизмерим с гарантийным сроком их эксплуатации. Для выполнения поставленных условий представляется иелесообразным разработка таких конструкций солнечных коллекторов, которые позволяли бы минимизировать затраты на их изготовление, монтаж и обслуживание. Это может достигаться за счет использования дешёвых отечественных материалов, выпуск которых гарантирован в достаточных объемах на протяжении длительного срока. Разработка, изготовление и внедрение двухконтурных солнечных установок позволило круглогодично эксплуатировать солнечный коллектор, но капитальные и эксплуатационные затраты при этом были на таком уровне, что для полной окупаемости солнечной установки могло понадобиться более
\end{abstract}


пяти лет, так как солнечные коллектора изготавливались из металла. В рамках сформулированной задачи нами был разработан и изготовлен солнечный коллектор из полиэтиленовой пленки.

Предлагается двухконтурная солнечная установка для горячего водоснабжения и отопления, у которой солнечные коллектора изготовлены из полиэтиленовой пленки. Такая установка разработана, изготовлена и запущена в эксплуатацию в одном южном регионе Украины. На установке были получень экспериментальные результаты работы установки в разных режимах в течение года. После обработки этих данных были получены обобщающие зависимости: плотности теплового потока от температуры теплоносителя в коллекторе, времени работы установки в течение светового дня и расхода теплоносителя; коэффициента полезного действия от плотности теплового потока; максимального коэффициента полезного действия от максимальной плотности теплового потока; количества теплоты при конвекции от скорости натекания ветрового потока от 1 до $6 \mathrm{~m} / \mathrm{c}$ на внешнюю поверхность солнечного коллектора. Зависимости получены при разных объемных расходах $\mathrm{V}$ от 0,5 до 3,0 $\mathrm{M}^{3} /$ ч теплоносителя. Максимальная погрешность проведенных расчетов не превышает $5 \%$.

Ключевые слова: интеграция, солнечные установки, двух контурные установки, возобновляемые источники энергии, солнечный коллектор.

\title{
INTEGRATION OF HEATTRANSFER PROCESS IN SUN INSTALLATION
}

\author{
Selikhov Yu.A., PhD in Tech.Sci., professor, Kotsarenko V.A., PhD in Tech.Sci., professor \\ National Technical University "Kharkov Polytechnic Institute", Kharkov, Ukraine
}

\begin{abstract}
European countries demonstrate high opportunities for simple conversion of solar energy into thermal energy, which can be successfully used to provide various types of technological, heating and domestic needs. In addition, the commissioning of salt plants improves the ecological situation in the area of consumption of thermal energy by reducing emissions of polluting substances, which include combustion products of organic fuel used for the production of thermal energy. At present, solar installations for hot water supply and heating are already used in the southern regions of Ukraine. However, the introduction of new energy and economically advantageous plants is proceeding slowly, which is explained by rather high cost indices, both domestic and foreign installations.Thus, in our opinion, the concept of creating new solar installations that are most attractive to a potential consumer is relevant. Implementation of this concept is possible with such an option of solar installations, when the cost of generating thermal energy using these facilities will be lower than the total cost of obtaining thermal energy by traditional methods (in particular, in boiler plants). However, with this, the payback period of solar installations should be commensurate with the warranty period of their operation. To fulfill the set conditions it is advisable to develop such designs of solar collectors that would allow to minimize the costs of their manufacture, installation and maintenance. This can be achieved through the use of cheap domestic materials, the release of which is guaranteed in sufficient quantities over a long period. The development, production and implementation of dual-circuit solar installations allowed the solar collector to be operated year-round, but the capital and operating costs were at such a level that it would take more than five years to fully pay for the solar installation, since the solar collectors were made of metal. Within the framework of the formulated task, we developed and manufactured a solar collector made of polyethylene film. A double-circuit solar installation is proposed for hot water supply and heating, in which the solar collectors are made of polyethylene film. Such an installation is designed, manufactured and commissioned in one southern region of Ukraine. Experimental results of the installation in different modes during the year were obtained at the plant. After processing of these data, generalizing dependencies were obtained: the heat flux density from the coolant temperature in the collector, the operating time of the installation during the daylight and the flow of the coolant; coefficient of efficiency from the density of heat flow; the maximum efficiency from the maximum heat flux density; the amount of heat in convection from the rate of leakage of the wind flow from 1 to $6 \mathrm{~m} / \mathrm{s}$ on the outer surface of the solar collector. Dependencies were obtained at different volumetric flows $V$ from 0.5 to $3.0 \mathrm{~m} 3 / \mathrm{h}$ of the heat carrier. The maximum error in the calculations does not exceed $5 \%$.
\end{abstract}

Keywords: integration, solar installations, two circuit installations, renewable energy sources, solar collector.

Постановка проблемы. Интенсивное использование традиционных источников энергии в мире привело к появлению ряда экологических проблем, наиболее острыми из которых являются: увеличение выбросов в атмосферу углекислого газа и уменьшение толщины озонового слоя. Сегодня, когда растет стоимость традиционных источников энергии, а запасы их исчерпываются, первоочередным вопросом является использование альтернативных или нетрадиционных источников энергии, таких как солнечная, ветровая, геотермальная, биоэнергия и фотосинтез. Наиболее мощным источником энергии для человечества является Солнце, большая активность которого будет сохраняться еще по меньшей мере 3-4 миллиарда лет. Количество солнечной энергии, которая попадает на землю, почти в 15000 раз превышает

\footnotetext{
Наукові праці, Том 82, випуск 1
}

Scientific Works, Volume 82, Issue 1 
потребности населения нашей планеты, однако лишь незначительная ее часть используется на хозяйственные нужды. Самым простым и эффективным способом использования энергии Солнца является превращение ее в тепловую энергию в солнечных коллекторах. На данное время разработано и используется значительное количество солнечных коллекторов разных конструкций, что отличает их по техникоэкономическим показателям. Подавляющее большинство солнечных коллекторов изготовляются в форме плоских конструкций, площадь поверхности которых является определяющим фактором в оценке количества как падающей на нее солнечной энергии, так и эффективности превращения ее в тепловую энергию [1]. Поэтому, развитие и совершенствование нетрадиционных способов получения тепловой энергии, внедрение солнечных установок для получения тепловой низкопотенциальной энергии, которая используется для горячего водоснабжения и отопления объектов различного назначения, а также улучшение экологической обстановки региона, в котором используются солнечные установки, - являются актуальными задачами.

Анализ последних исследований и публикаций. Солнечные коллектора изготавливаются из различных материалов: обычный черный металл, нержавеющая сталь, алюминий, медь и полимерные материалы [2, 3], которые, как правило, предназначены для конкретных гелиотехнических установок и отличаются по технологическим, эксплуатационным и технико-экономическим параметрам. Нами был проведен анализ работы существующих солнечных установок и были выявлены их недостатки. Они были учтены при разработке новой конструкции солнечной установки. Хотя принцип работы солнечных коллекторов простой, разработано огромное количество разных конструкций солнечных коллекторов из разного металла, а в технической литературе приведено много экспериментальных исследований работы солнечных коллекторов, изготовленных из разных металлов, в разных регионах с разной солнечной активностью. Однако обобщающих зависимостей, что описывают взаимосвязь основных параметров эффективности солнечных установок для коллекторов, изготовленных из полимерных материалов: зависимость плотности теплового потока от температуры теплоносителя и времени суток работы солнечной установки при разных расходах теплоносителя; зависимость коэффициента полезного действия (КПД) от плотности теплового потока при разных расходах теплоносителя в коллекторе; зависимость максимального коэффициента полезного действия от максимальной плотности теплового потока при разных расходах теплоносителя, мы не встречали.

Цель статьи. В данной работе авторами предлагается разработанная, изготовленная и запущенная в эксплуатацию двухконтурная солнечная установка в одном южном регионе Украины. В результате эксплуатации установки нами были получены экспериментальные результаты работы установки в различных режимах. Установка представлена на рисунке 1.



Рис. 1. Принципиальная технологическая схема двухконтурной солнечной установки для отопления помещений СК - солнечный коллектор; БА1, БА2 - баки-аккумуляторы; Н1, Н2, Н3, Н4 циркуляционные насосы; ВР - вентиль регулировочный; В31 В334 - вентили запорные; К - калорифер; В - вентилятор; Т - теплообменный аппарат; ХВО - аппарат химводоочистки; 1, 3, 6, 7 холодный теплоноситель; 2 - антифриз; 4,8 - воздух; 5 - солнечное излучение.

Сделаем описание вариантов работы новой технологической схемы, которая представлена на рис.1. Солнечная установка может работать как сезонно, так и круглогодично. Сезонная работа. По первому варианту антифриз из первого контура теплообменника Т через вентили запорные В37, В36 и В35 циркуляционным насосом Н1 подается в солнечный коллектор СК, где он нагревается до необходимой температуры и обратно поступает в первый контур теплообменника Т. Нагретый антифриз отдает свое тепло

Наукові праці, Том 82, випуск 1

Scientific Works, Volume 82, Issue 1 
во втором контуре теплообменника Т теплоносителю (воде), подающемуся циркуляционным насосом Н2 через вентили запорные В33, В34 и В38 из бака-аккумулятора БА1 в теплообменник Т и далее поступает обратно в теплообменник Т. В третьем варианте холодный теплоноситель из сетевого трубопровода через вентиль запорный В31 подается в аппарат химводоочистки ХВО, где теплоноситель очищается от многих солей и далее через вентиль запорный В32 и вентиль регулировочный ВР поступает и наполняет бак-аккумулятор БА1. В выбранном нами баке-аккумуляторе происходит накопление и прямое аккумулирование тепла, поскольку аккумулирующей и теплообменной является одна и та же среда. В случае аварийной ситуации есть возможность выпустить теплоноситель в канализацию через вентиль запорный B312.

Для круглогодичной работы. В четвертом варианте теплоноситель (горячая вода) из бакааккумулятора БА1 через вентили запорные В39 и В310 циркуляционным насосом Н3 подается в калорифер К и далее через вентиль запорный В311 обратно в бак-аккумулятор БА1. В пятом варианте холодный воздух из приточной вентиляции через вентили запорные В320 и В317 вентилятором В через вентиль запорный В318 подается в калорифер К, где нагревается горячей водой и через вентиль запорный В319 подается для нагрева помещения. Когда необходимо нагреть теплоноситель до более высокой температуры в работу включается шестой вариант.

Теплоноситель через вентили запорные В313 и В314 циркуляционным насосом Н4 направляется в бак-аккумулятор БА2, где нагревается электронагревателями до необходимой температуры и далее через вентиль запорный В315 подается к потребителю (на отопление помещений, на кухню). Оборотная вода через вентиль запорный В316 возвращается обратно в бак-аккумулятор БА1. Мы также заменили плоские металлические коллектора на гибкие полимерные, двухконтурные теплообменные аппараты на скоростные пластинчатые аппараты.

Рассмотренный солнечный коллектор СК выполнен из полиэтиленовой пленки черного матового цвета [4] специальной конструкции, которая уложена в теплоизолированный со всех сторон пенополистиролом толщиной 30 мм металлический корпус [5]. Площадь тепловоспринимающей поверхности солнечного коллектора равна - $210 \mathrm{~m}^{2}$ и состоит из 21 секции. То есть, в 21 металлическом корпусе находится 21 секция гибкого полимерного коллектора.

Сверху каждый металлический корпус закрыт оконным стеклом толщиной 4 мм и фиксируется к корпусу с помощью прижимных планок. Испытания проводились при разных объемных расходах теплоносителя, в качестве которого применялась вода. Контроль и сбор информации о параметрах теплоносителя (расход, температура) осуществлялся системой автоматизированного управления солнечной установкой. Конструкция солнечного коллектора позволяет производить ремонт посекционно, не отключая всей установки. А в случае закупоривания проходных сечений коллектора накипью, которая образуется в каналах, т.к. температура теплоносителя повышается до $90{ }^{\circ} \mathrm{C}$, секция коллектора отключается автономно, очищается и устанавливается на прежнее место или заменяется новым коллектором.

В настоящей статье также рассматривается вопрос обобщения экспериментальных данных, полученных для различных постоянных расходов теплоносителя $(V)$ : с целью получения зависимостей: плотности теплового потока $(q)$ от температуры теплоносителя $(t)$ в коллекторе и времени работы установки в течение светового дня ( $\tau)$; КПД $(\eta)$ от плотности теплового потока $(q)$; максимального


вым потоком с внешней поверхности стекла солнечного коллектора от скорости ветрового потока $(V)$.

Одной из основных характеристик эффективности работы солнечного коллектора является изменение плотности теплового потока $(q)$ от температуры теплоносителя $(t)$ в коллекторе и времени работы установки в течение светового дня $(\tau)$ при разных объемных расходах $(V)$ теплоносителя, которое представлено на рис. 2. Нами был выполнен анализ экспериментальных данных при изменении постоянного расхода $V$ теплоносителя от 0,5 до $3,0 \mathrm{~m}^{3} /$ ч $(1-0,5 ; 2-1 ; 3-1,5 ; 4-2 ; 5-2,5 ; 6-3,0)$ и получены обобщающие зависимости вида $q=f(t, \tau)$ при $V=$ const. Номера в скобках соответствуют номерам на кривых рис. 2 .

Нами были выполнены теплотехнические расчеты экспериментальных данных при изменении расхода $V$ теплоносителя от 0,5 до $3,0 \mathrm{~m}^{3} /$ ч и получены обобщающие зависимости вида $q=f(t, \tau)$ при $V=$ const. При анализе экспериментальных данных с целью представления в аналитическом виде функциональной зависимости, т. е. в подборе формулы, описывающей результаты эксперимента, были использованы возможности надстройки среды Excel (пакет анализа), а именно регрессионный анализ [6].

Инструменты регрессионного анализа позволяют анализировать большие совокупности данных не только для получения основных статистических характеристик и построения соответствующих кривых зависимости (линии регрессии) для визуальной оценки, но и найти уравнение, которое наилучшим образом отображает множество данных, которые математически описывают влияние ряда независимых переменных на ожидаемый результат. 


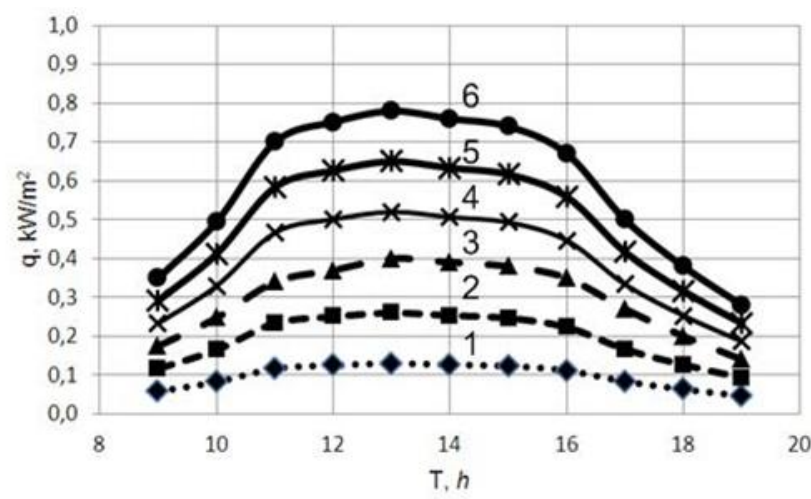

Рис. 2. Изменение плотности теплового потока.

Ниже приведены функциональные зависимости вида $q=f(t, \tau)$ для постоянных значений $V$.

$$
\begin{aligned}
& q=0,010339 \cdot 1,027805^{t} \cdot 1,01145^{\tau} \\
& q=0,02069 \cdot 1,021806^{t} \cdot 1,011405^{\tau} \\
& q=0,026081 \cdot 1,02701^{t} \cdot 1,032366^{\tau} \\
& q=0,041415 \cdot 1,021796^{t} \cdot 1,011428^{\tau} \\
& q=0,051707 \cdot 1,027809^{t} \cdot 1,011443^{\tau} \\
& q=0,06211 \cdot 1,0278^{t} \cdot 1,011416^{\tau}
\end{aligned}
$$

Еще одной характеристикой эффективности работы солнечного коллектора является изменение коэффициента полезного действия при изменении плотности теплового потока, которое представлено на рисунке 3.

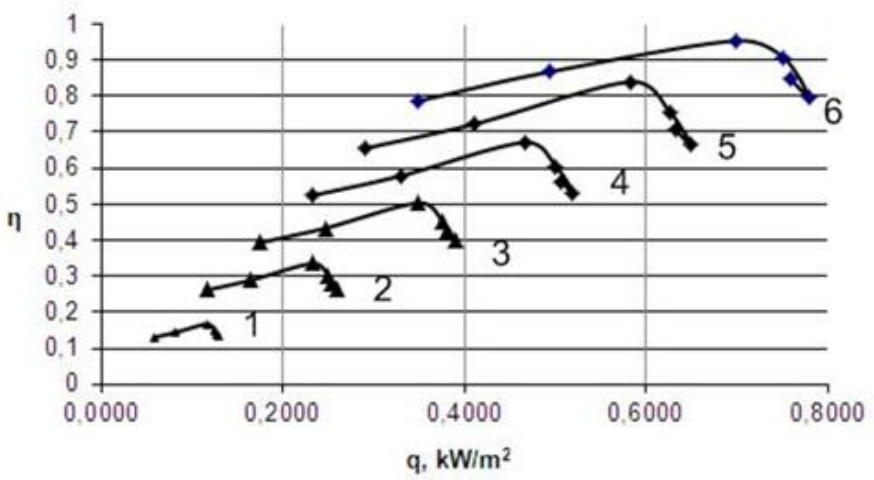

Рис. 3. Изменение коэффициента полезного действия при изменении плотности теплового потока. при $V\left(\mathrm{м}^{3} /\right.$ ч) $=$ const: $1-0,5 ; 2-1 ; 3-1,5 ; 4-2 ; 5-2,5 ; 6-3,0$.

Нами был выполнен анализ экспериментальных данных, представленных на рисунке 3, и получены обобщающие зависимости вида $\eta=f(q)$ при $V=$ const. Номера в скобках соответствуют номерам на кривых рис. 3.

Ниже приведены уравнения, которые описывают $\eta=f(q)$ при $V=$ const:

$$
\begin{aligned}
& \text { КПД( })=0,68-1022 q^{3}+264,99 q^{2}-21,4 q \quad R^{2}=0,98 \\
& \text { КПД( })=1,3-255,04 q^{3}+132,45 q^{2}-21,39 q R^{2}=0,98 \\
& \text { КПД( })=2,04-113,45 q^{3}+88,28 q^{2}-21,4 q \quad R^{2}=0,98
\end{aligned}
$$




$$
\begin{aligned}
& \text { КПД( })=2,72-63,83 q^{3}+66,22 q^{2}-21,4 q \quad R^{2}=0,98 \\
& \text { КПД( })=3,4-40,8 q^{3}+52,92 q^{2}-21,38 q \quad R^{2}=0,98 \\
& \text { КПД( })=2,95-19,72 q^{3}+30,94 q^{2}-14,34 q \quad R^{2}=0,95
\end{aligned}
$$

где $R^{2}$ - коэффициент корреляции.

Как видно, при анализе коэффициентов корреляции погрешность расчетов не превышает 5 \%. Сделав анализ зависимостей на рисунке 3 , мы построили зависимость максимального коэффициента полезного действия от максимальной плотности теплового потока при разных объемных расходах теплоносителя, которая представлена на рисунке 4.

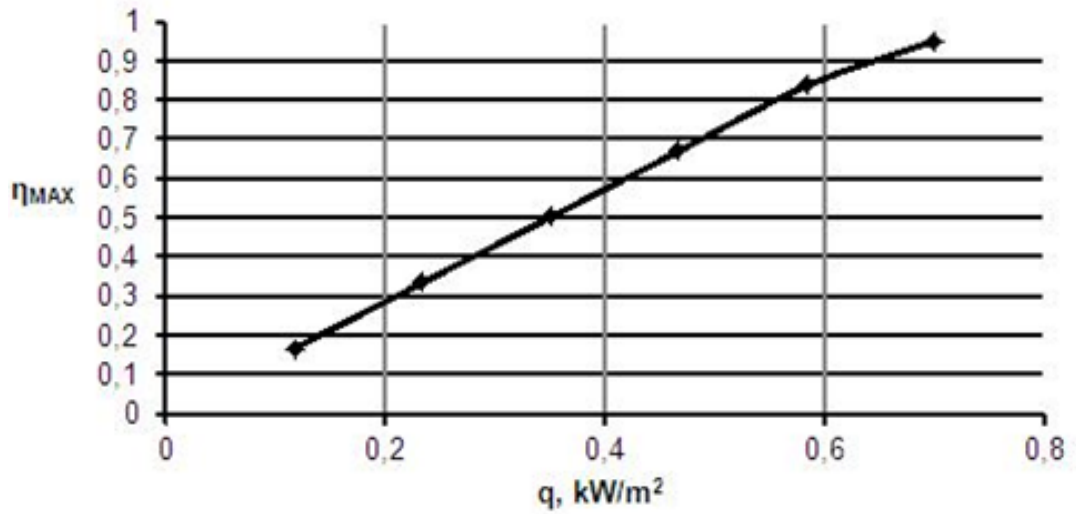

Рис. 4. Изменение максимального коэффициента полезного действия от максимальной плотности теплового потока при разных объемных расходах V от 0,5 до $3,0 \mathrm{~m}^{3} / 4$.

Как видно из рисунка 4 зависимость максимального коэффициента полезного действия (ๆ) от максимальной плотности теплового потока $(q)$ носит линейный характер и может быть представлена уравнением: КПД $(\eta)=1,37 \cdot q+0,018$, с коэффициентом корреляции $R^{2}=0,99$, это показывает, что погрешность расчетов не превышает $1 \%$.

Обобщенное уравнение количества теплоты $(Q$, кВт), уносимого ветровым потоком с внешней поверхности стекла солнечного коллектора от скорости ветрового потока $(V, \mathrm{~m} / \mathrm{c})$ представлено уравнением

$$
Q=165,27 \cdot \ln (V)+69,445 \text {, }
$$

где $R^{2}=0,99$, это показывает, что погрешность расчетов не превышает $1 \%$.

Выводы. 1. Разработана, изготовлена и запущена в эксплуатацию новая солнечная установка из новых материалов. 2. Получены обобщающие зависимости: плотности теплового потока от температуры теплоносителя в коллекторе, времени работы установки в течение светового дня и расхода теплоносителя; коэффициента полезного действия от плотности теплового потока; максимального коэффициента полезного действия от максимальной плотности теплового потока; количества теплоты, уносимого ветровым потоком с внешней поверхности стекла солнечного коллектора от скорости ветрового потока. Зависимости получены при разных объемных расходах $V$ от 0,5 до $3,0 \mathrm{~m}^{3} /$ ч теплоносителя. Максимальная погрешность проведенных расчетов не превышает 5 \%. 3. Проведенные исследования показали, что для всех типов полимерных материалов при разных объемных расходах $V$ от 0,5 до 3,0 м 3 чч теплоносителя можно рассчитать: плотность теплового потока по условиям теплообмена на входе в коллектор; максимальный коэффициент полезного действия по максимальной плотности теплового потока и расходу теплоносителя; количество теплоты, которое теряется во время работы солнечной установки. 4. Натурные испытания показали, что коллектор из полимерного материала наиболее полно поглощает тепло солнечного излучения, это приводит к нагреву теплоносителя до более высоких температур $\left(90{ }^{\circ} \mathrm{C}\right)$ по сравнению с конструкциями солнечных коллекторов, изготовленных из разных металлов $\left(63{ }^{\circ} \mathrm{C}\right) .5$. Применение солнечных коллекторов из полимерных материалов позволяет уменьшить: себестоимость получаемой тепловой энергии; материалоемкость солнечной установки; срок окупаемости солнечной установки; упростить схему ее работы; усовершенствовать действующие солнечные установки. 
Литература

1.Концепция государственной энергетической политики Украины на период до 2020 г. // Информационное приложение. 2001. - № 10. - 8 c.

2. Даффи Дж., Бекман У.А. Тепловые процессы с использованием солнечной энергии. - М.: Мир, $1977 .-420$ с.

3.Селихов Ю.А., Ведь В.Е., Бухкало С.И., Костин В.М. Конструкционные особенности увеличения эффективности работы гелиоустановок. Экотехнологии и ресурсосбережение. - Киев: Типография НАН Украины, № 3, 2004. - С. 70-75.

4. Полімерна композиція: пат. 72078 А Україна. №2003088001 ; заявл. 27.08.2003 ; опубл. 17.01.2005, Бюл. № 1. 110 с.

5. Геліоводонагрівник: пат. 75178 Україна. № 2004021010 ; заявл. 12.02.2004 ; опубл. 15.03.2006, Бюл.

№ 3,120 c.

6. Коцаренко В.О., Селіхов Ю.А., Горбунов К.О. Розрахунки в середовищі Ехсеl: навч. посіб. - Харків: Вид-во «Підручник НТУ «ХПІ»», 2011. - $272 \mathrm{c}$.

\title{
References
}

1. (2001) Contseptsiya gosudarstvennoy energetichkoy politiki Ukrainy na period do $2020 \mathrm{~g}$. Informatsionnoe priloghenie.10. 8 .

2. Daffi Dzh., Bekman U.A. (1977) Teplovye protsesy s ispolzovaniem solnechoy energii. Moskow Mir,. 420.

3. Selikhov Yu. A., Ved V.E., Bukhkalo S. I., Kostin V. M. (2004) Consruktsonnie osobennosti uvelicheniy efektivnosti raboti gelioustanovok. Ekotekhnologii i resursosberezhenie. Kiev: Tipografia NAN Ukrainy. 3. 70-75.

4. Polimerna compozitsiya: pat. № 72078 A Ukrainy. №2003088001 ; zayavl. 27.08.2003 ; opubl. 17.01.2005, Byul. № 1. 110

5. Geliovodonagrivnyk: pat. № 75178 Ukrainy. № 2004021010 ; zayavl. 12.02.2004 ; opubl. 15.03.2006,

Byul. № 3, $120 \mathrm{~s}$.

6. Kotsarenko V.O., Selikhov Yu. A., Gorbunov K.O. (2011) Rozrakhky v seredovyschi Excel: navch. Posib. - Kharkiv: Vyd-vo «Pidruchnyk NTY «KhPI», 272.

\section{ДОСЛІДЖЕННЯ ПРОЦЕСІВ КОМПОСТУВАННЯ ХАРЧОВОЇ СКЛАДОВОЇ ТВЕРДИХ МУНІЦИПАЛЬНИХ ВІДХОДІВ З ВИКОРИСТАННЯМ МІНЕРАЛЬНИХ ДОБАВОК}

\author{
Крусір Г.В., д.т.н., професор, Сагдєєва О.А., Чернишова О.О., асистент, Мадані М.М., к.Т.н., доцент, \\ Гаркович О.Л., к.б.н., доцент \\ Одеська національна академія харчових технологій, м. Одеса
}

\begin{abstract}
Анотація. Ефективне управління твердими муніципальними відходами є першочерговим завданням у сфері міжнародної та національної екологічної безпеки. В Украӥні воно фактично вирішується через зберігання сотень тисяч відходів на керованих та некерованих звалищах та полігонах.

Оскільки до 40\% твердих муніципальних відходів відноситься до органічних, щзо легко розкладаються (харчові відходи, відходи ринків, домогосподарств, міських зелених господарств, муніџипальної мережі харчування), вилучення цієї частини відходів зі звалищ за рахунок компостування суттєво зменшить навантаження на фактично розмішенні та потенційно заплановані звалищза.

Аеробне компостування є однією з найкращих найбільш доступних технологій для інтегрованої системи управління відходами за рахунок мінімізації антропогенного впливу на довкілля, відповідності новітнім вітчизняним та зарубіжним розробкам, економічної та практичної прийнятності технології.

Метою експериментального дослідження було вивчення можливості прискорення прочесу компостування харчової складової твердих муніципальних відходів за рахунок внесення мінеральних добавок для впровадження в якості природоохоронної технологї̈ на звалищах.

У статті представлено результати дослідження впливу мінеральної добавки на перебіг процесів компостування харчової складової твердих муніципальних відходів з метою його прискорення в мезофільному і термофільному температурних режимах з керованими параметрами. Для підвищення ефективності процесу компостування та порівняння особливостей перебігу процесів в якості мікробіологічного інокуляту використовували трунт, в якості мінеральної добавки - розчини мінеральних солей.

Показано, щзо мінеральний комплекс прискорює прочес компостування харчової складової твердих побутових відходів в 2,2 рази за термофільного режиму і в 1,4 рази за мезофільних умов проведення процесу компостування, щзо свідчить про ефективність його використання в процесах переробки твердих муніцииальних відходів з метою підвищення загального рівня екологічної безпеки.

Ключові слова: компостування; відходи; суміш, що компостується; мінеральна добавка; мезофільний і термофільний режими компостування
\end{abstract}

